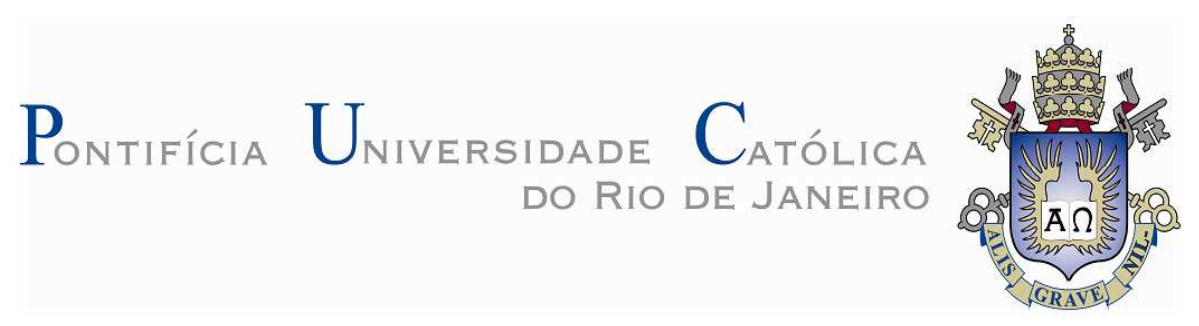

Yohn Edison Polo Garzon

\title{
Retroanálise da Cortina Instrumentada da Ferrovia São Paulo - Santos (FEPASA - KM 74)
}

Dissertação apresentada como requisito parcial para obtenção do grau de Mestre pelo Programa de Pós-Graduação em Engenharia Civil do Departamento de Engenharia Civil da PUC-Rio.

Orientador: Prof. Celso Romanel Co-Orientador: Prof. Pedricto Rocha Filho 


\title{
Pontifícia Universidade Católica $_{\text {an }}$ \\ DO RIO DE JANEIRO

\section{Yohn Edison Polo Garzon}

\author{
Retroanálise da Cortina Instrumentada da \\ Ferrovia São Paulo - Santos (FEPASA - KM 74) \\ Dissertação apresentada como requisito parcial \\ para obtenção do grau de Mestre pelo Programa \\ de Pós-Graduação em Engenharia Civil do \\ Departamento de Engenharia Civil do Centro \\ Técnico da PUC-Rio. Aprovada pela Comissão \\ Examinadora abaixo assinada.
}

\author{
Prof. Celso Romanel \\ Orientador \\ Departamento de Engenharia Civil - PUC-Rio \\ Prof. Pedricto Rocha Filho \\ Co-Orientador \\ Departamento de Engenharia Civil - PUC-Rio
}

Prof. José Tavares Araruna Júnior Departamento de Engenharia Civil - PUC-Rio

Prof. Fernando Saboya Albuquerque Júnior Universidade Estadual do Norte Fluminense

Prof. José Eugenio Leal Coordenador Setorial do Centro Técnico Científico - PUC-Rio

Rio de Janeiro, 20 Julho de 2015. 
Todos os direitos reservados. É proibida a reprodução total ou parcial do trabalho sem autorização da universidade, do autor e do orientador.

\section{Yohn Edison Polo Garzon}

Graduou-se em Engenharia Civil pela Universidade Nacional da Colômbia (Sede Manizales) em 2010. Ingressou no mesmo ano ao curso de especialização em Ruas e Transporte na mesma universidade. Ingressou no mestrado de engenharia civil em 2013, na Pontifícia Universidade Católica do Rio, desenvolvendo Dissertação na linha de pesquisa de Geotécnica Experimental.

Ficha Catalográfica

Garzon, Yohn Edison Polo

Retroanálise da Cortina Instrumentada da Ferrovia São Paulo - Santos (FEPASA - KM 74) / Yohn Edison Polo Garzon; Orientador: Celso Romanel; Co-orientador: Pedricto Rocha Filho. - Rio de Janeiro: PUC-Rio, Departamento de Engenharia Civil, 2015.

(161) f. : il. (color.) ; $30 \mathrm{~cm}$

Dissertação (Mestrado) - Pontifícia Universidade Católica do Rio de Janeiro, Departamento de Engenharia Civil, 2015.

Inclui referências bibliográficas

1. Engenharia civil - Teses. 2. Instrumentação. 3. Estruturas de contenção. 4. Tirantes. 5. Eletroníveis. I. Romanel, Celso. II. Filho, Rocha Pedricto. III. Pontifícia Universidade Católica do Rio de Janeiro. Departamento de Engenharia Civil. IV. Título. 
A Deus, a meus pais, Emilio e Gloria, as meus anjos Sofia e Gabriel, a minha esposa, Johana, a meu irmão e meu sobrinho, Faber e Nicolas 


\section{Agradecimentos}

Primeiro agradeço a Deus pela vida e pela saúde, e por me dar tantas oportunidades maravilhosas na vida toda.

Para os meus pais Emilio e Gloria, quem com seu exemplo da vida criaram em mim os melhores valores como pessoa.

Para minha esposa Johana e minha filha Sofia, quem deixaram seu país e sua casa, para vir e acompanhar-me neste tempo, seu apoio foi essencial.

Ao professor Pedricto Rocha, obrigado pela oportunidade de trabalhar com você, sem dúvida sem seu apoio acadêmico não houvera sido possível a finalização de meu mestrado.

Ao professor Luis Gusmão pela sua orientação e ajuda no manejo dos eletroníveis e do sistema de aquisição de dados.

Aos professores da pós-graduação da PUC-Rio, que em cada aula entregam mais do que conhecimento, entregam sua experiência e qualidade de pessoas, obrigado por tudo o ensinado nesses anos.

Ao meu grande amigo Francisco Cruz, quem virou um anjo para nossa família, Deus abençoe sempre.

Aos meus caros amigos, Daniel Velez, Juan Manuel, Laura, Nelson, Juan Pablo, que com sua amizade, carinho e apoio, fizeram deste tempo, um tempo mais grato.

A todos os funcionários do Departamento de Engenharia Civil da PUC-Río, em especial à Rita Leite.

A CAPES e a PUC-Rio, pelos auxílios concedidos, sem os quais este trabalho não poderia ter sido realizado. 


\section{Resumo}

Polo Garzon, Yohn Edison; Romanel, Celso; Rocha filho, Pedricto. Retroanálise da Cortina Instrumentada da Ferrovia São Paulo Santos (FEPASA - KM 74). Rio de Janeiro, 2015. 161 p. Dissertação de Mestrado. Departamento de Engenharia Civil, Pontifícia Universidade Católica do Rio de Janeiro.

O presente trabalho apresenta um estudo sobre uma estrutura de contenção projetada para a duplicação da ferrovia FEPASA no Km 74 entre Santos e São Paulo, que consiste em uma cortina ancorada por tirantes. Essa estrutura foi instrumentada a fim de se medirem as cargas nos tirantes com uso de células de carga elétricas instaladas na cabeça dos mesmos. As medições de carga nos tirantes foram feitas durante os ensaios de recebimento, no momento da incorporação e também após a conclusão da obra. As cargas nos tirantes sofrem redução de seu valor no momento imediato a sua incorporação, durante a construção e após da data de terminação das obras da cortina. Constatou-se que houve perda de carga nos tirantes ao longo do tempo, chegando a 54\% de perda em um deles. Enfatizando a importância da instrumentação de campo para compreender melhor o comportamento das estruturas, na parte inicial desta dissertação é apresentado um desenvolvimento teórico e calibração de dezesseis eletroníveis como proposta para a medição de deslocamentos horizontais em obras geotécnicas.

\section{Palavras-chave}

Instrumentação; Estrutura de contenção; Tirantes, Eletroníveis. 


\section{Abstract}

Garzon, Yohn Edison Polo; Romanel, Celso (Advisor); Rocha filho, Pedricto (Co-Advisor). Backanalysis of the São Paulo - Santos Railway Anchored Wall (FEPASA - KM 74). Rio de Janeiro, 2015. 161 p. Dissertação de Mestrado. Departamento de Engenharia Civil, Pontifícia Universidade Católica do Rio de Janeiro.

This work presents a study about a retaining structure designed for the duplication of the rail FEPASA on the 74th $\mathrm{km}$ between Santos and São Paulo. This structure, an anchored retaining wall, was instrumented in the anchors heads with strain gauges in order to monitor its loads. The load measurements occurred during the performance test, locking and also after the works were concluded. A decrease on anchors loads is noticed in the moment immediately after the locking, during construction and after the works finished. It was observed that a loss of load in the anchors occurred to a maximum of $54 \%$. Highlighting the relevance of field monitoring to better understand the structures behavior, in the first part of this dissertation we present a theoretical background as well as the calibration of sixteen electrolevels as a proposal for the measurement of horizontal displacements in Geotechnical works.

\section{Keywords}

Instrumentation; Retaining wall; Anchors, Electrolevels. 


\section{Sumário}

1. Introdução 21

1.1. Comentários gerais 21

1.2. Objetivos 22

1.3. Organização do trabalho 23

2. Revisão Bibliográfica 25

2.1. Introdução 25

2.2. Conceitos básicos em instrumentação 26

2.3. Critérios para execução 30

2.4. Frequência de leitura 33

2.5. Medidores de deslocamentos 34

2.5.1. Conceitos de Instrumentos 34

$\begin{array}{ll}\text { 2.5.2. Alguns equipamentos utilizados } & 37\end{array}$

2.6. Cortinas Ancoradas 42

2.6.1. Tirantes 43

2.6.2. Modos de Ruptura em Cortinas Ancoradas 48

2.6.3. Cálculo do Empuxo Sobre a Cortina 49

2.6.4. Método de Costa Nunes e Velloso (1963) 53

2.6.5. Análise da estabilidade global do sistema de contenção 54

2.6.6. Capacidade de carga das ancoragens 57

2.6.7. Deslocamentos em Estruturas de Contenção e Movimentos de Solo Associados 62

$\begin{array}{ll}\text { 2.6.8. Cargas em Tirantes } & 75\end{array}$

3. Eletroníveis: Montagem, princípio de funcionamento, calibração e sistema de aquisição de dados. 79

3.1. Introdução 79

3.2. Princípio básico de funcionamento dos eletroníveis 80

3.3. Montagem 84 
3.4. Procedimento de calibração 84

3.4.1. Eletronível de referência 87

3.4.2. Eletroníveis A01 a A16 89

3.5. Sistema de aquisição de dados 91

3.5.1. Data logger $\quad 91$

3.5.2. Sistema de Monitoramento de Eletroníveis 93

4. Aspectos Gerais da Obra Estudada. 95

4.1. Cortina Ancorada 95

4.2. Tirantes Utilizados 98

4.2.1. Materiais 98

4.2.2. Montagem dos Tirantes 98

4.2.3. Instalação dos Tirantes 102

4.3. Sequência de construção 104

4.4. Caracterização do subsolo 106

4.5. Descrição Geral da Instrumentação da estrutura de

Contenção 108

5. Resultados e Análises. 112

5.1. Ensaios de Recebimento Característicos dos Tirantes. 112

5.1.1. Ensaios abaixo da "Linha C" 113

5.1.2. Ensaios pertos da "Linha A" 115

5.1.3. Ensaios acima da "Linha C". 117

5.1.4. Ensaios pertos da "Linha B". 118

5.2. Análises da Capacidade de Carga dos Tirantes 121

5.2.1. Método da NBR 5629 (2006) 121

5.2.2. Método de Ostermayer (1975) 123

5.2.3. Método de Bustamante e Doix (1985) 124

5.3. Comportamento dos Tirantes Instrumentados $\quad 125$

5.3.1. Seção 34 da Cortina.

5.3.2. Seção 38 da Cortina. $\quad 127$

5.3.3. Seção 45 da Cortina. $\quad 128$

5.3.4. Seção 48 da Cortina. $\quad 130$

5.3.5. Seção 51 da Cortina. 131 
5.3.6. Seção 54 da Cortina.

5.3.7. Seção 57 da Cortina.

5.3.8. Seção 60 da Cortina. 136

5.3.9. Seção 66 da Cortina. 138

5.3.10. Seção 69 da Cortina.

5.4. Comparação entre os valores de carga medidos e os teóricos encontrados na literatura.

5.4.1. Verificação da Estabilidade pelo Método de Costa Nunes e Velloso (1963)

5.4.2. Forças nos tirantes pelo diagrama de empuxo proposto por Terzaghi e Peck (1967) e pela FHWA (USA 1999). 143

5.4.3. Retroanálise dos parâmetros de resistência 148

6. Conclusões e Sugestões. 151

6.1. Conclusões 151

6.2. Sugestões 153

$\begin{array}{ll}\text { Referência s Bibliográficas } & 154\end{array}$ 


\section{Lista de Figuras}

Figura 1. Diferencia entre exatidão e precisão (Dunnicliff 1988).

Figura 2. Transdutor pneumático fechado com dois tubos e leitura de fluxo de gás (Dunnicliff, 1988) 35

Figura 3. Esquema do sensor de corda vibrante (Dunnicliff, 1988) 35

Figura 4. Esquema de LVDT (Dunnicliff. 1988) 37

Figura 5. Extensômetro magnético (Gil et. al., 2008) 38

Figura 6. Componentes do Extensômetro Horizontal de Hastas Múltiplas (Belitardo e Pereira, 2001, com modificações) 40

Figura 7. Principio de operação do inclinômetro (Dunnicliff, 1988) 42

Figura 8. Partes constituintes de um tirante (YASSUDA e DIAS, 1996).

Figura 9. Modos de ruptura em cortinas ancoradas (STROM e EBELING, 2002).

Figura 10. Diagramas empíricos de Terzaghi e Peck (1967).

Figura 11. Distribuição de tensões sobre cortina multiescorada, proposto por Gaba et al. (2003).

Figura 12. Análise de Estabilidade pelo método de Costa Nunes e Velloso (GeoRio, 2000).

Figura 13. Tipos de ruptura na análise de estabilidade global em estruturas ancoradas (More, 2003).

Figura 14. Superfície de ruptura interna simplificada (Yassuda e Dias, 1996).

Figura 15. Capacidade de carga de ancoragens executadas em solos argilosos. (Ostermayer, 1975)

Figura 16. Capacidade de carga de ancoragens executadas em solos granulares. (Ostermayer, 1975)

Figura 17. Correlações empíricas para determinação de qs em areias e pedregulhos (Bustamante e Doix, 1985, apud More, 2003).

Figura 18. Correlações empíricas para determinação de qs em siltes e argilas (Bustamante e Doix, 1985). 
Figura 19. Movimentos na superfície do solo, devido à construção de cortina de estacas em argila rija: (a) movimentos horizontais; (b) movimentos verticais (Gaba et al., 2003).

Figura 20. Comportamento de deslocamentos em estruturas de contenção ancoradas (Gaba et al., 2003).

Figura 21. Relação entre 0 fator de segurança contra levantamento de fundo, definido por Terzaghi (1943) e o máximo deslocamento horizontal da cortina (Mana e Clough, 1981).

Figura 22. Deslocamento lateral da parede como porcentagem da profundidade de escavação versus rigidez do sistema de suporte (Clough et al., 1989).

Figura 23. Máximos deslocamentos horizontais observados em cortinas para escavações em argila de Londres (St John et al., 1992).

Figura 24. Deslocamentos horizontais e verticais em paredes assentes em argila rija, devido à escavação em frente à cortina (Gaba et al., 2003).

Figura 25. Deslocamentos verticais em paredes assentes em areia, devido à escavação em frente à parede (Gaba et al., 2003).

Figura 26. Variação do máximo deslocamento horizontal com a profundidade de escavação (Moorman, 2004).

Figura 27. Valores de recalques superficiais obtidos por Wang et al. (2010), plotados no gráfico proposto por Peck (1969).

Figura 28. Deslocamentos máximos laterais versus profundidade de escavação: (a) cortinas construídas pelo método de escavação de cima para baixo; (b) cortinas relativamente rígidas construídas pelo método de baixo para cima; (c) cortinas de estacas metálicas (Wang et al., 2010).

Figura 29. Distribuição de carga ao longo do bulbo do tirante, medida por Li et al. (1988).

Figura 30. Distribuição de carga ao longo do tirante, medida por Briaud et al., 1998, para carga de trabalho igual a $400 \mathrm{kN}$.

Figura 31. Distribuição de carga ao longo do tirante, medida por Iten e Pzrin (2010); (a) 340 kN; (b) 400kN. 
Figura 32. Rotação de um corpo rígido (Toledo, 2009)

Figura 33. Vista do cilindro protetor (Dimensões em milímetros)

Figura 34. Detalhe da parte interna do cilindro.

Figura 35. Funcionamento do eletronível.

82

Figura 36. Detalhe da variação da altura do liquido eletrolítico entre os eletrodos.

82

Figura 37. Circuito elétrico de conexão dos eletroníveis com os condicionadores (Wha,1999).

Figura 38. Curvas de sensibilidade dos eletroníveis (www.frederickscom.com)

Figura 39. Barra de calibração dos eletroníveis (Laboratório PUCRio)

Figura 40. Calibração dos eletroníveis utilizando o SME. 85

Figura 41. Detalhe da fixação do eletronível à barra de calibração 86

Figura 42. Detalhe do sistema de calibração do eletronível.

Figura 43. Relação para as leituras do SME e Mini Data-logger para o eletronível de referência com valor médio de 3.67E-05

Figura 44. Curvas de calibração para os eletroníveis A01 a A16 90

Figura 45. Fatores de calibração dos eletroníveis A01 a A16

Figura 46. Detalhes do mini data logger e da conexão com os eletroníveis.

Figura 47. Vista dos equipamentos do Sistema de Monitoramento de Eletroníveis.

Figura 48. Esquema da Cortina Ancorada. (Adaptado de Zeitoune, 1982).

Figura 49. Seção típica da Cortina Ancorada. (Adaptado de Zeitoune, 1982).

Figura 50. Esquema do Tirante Tipo Utilizado. (Adaptado de Zeitoune, 1982).

Figura 51. Seção Transversal do Tirante Tipo Utilizado. (Adaptado de Zeitoune, 1982).

Figura 52. Detalhe "A" que apresenta o esquema do trecho ancorado dos tirantes. (Adaptado de Zeitoune, 1982). 
Figura 53. Seção geológico-geotécnica no local de estudo. (Adaptado de Zeitoune, 1982).

Figura 54. Esquema de instrumentação de tirante durante a sua protensão (Dunnicliff, 1988).

Figura 55. Ensaio de recebimento do tirante 57D, carga $x$ deslocamentos totais.

Figura 56. Repartição entre deslocamentos elásticos e plásticos do Tirante 57D, carga $\times$ deslocamentos totais.

Figura 57. Ensaio de recebimento do tirante 51D, carga $x$ deslocamentos totais.

Figura 58. Repartição entre deslocamentos elásticos e plásticos do Tirante 51D, carga $x$ deslocamentos totais.

Figura 59. Ensaio de recebimento do tirante $66 \mathrm{C}$, carga $x$ deslocamentos totais.

Figura 60. Repartição entre deslocamentos elásticos e plásticos do Tirante 66C, carga $\times$ deslocamentos totais.

Figura 61. Ensaio de recebimento do tirante $45 \mathrm{~A}$, carga $\mathrm{x}$ deslocamentos totais.

Figura 62. Repartição entre deslocamentos elásticos e plásticos do Tirante 45A, carga $x$ deslocamentos totais.

Figura 63. Capacidade de carga das ancoragens média de 550 para as condições do caso em estudo pelo Método de Ostermayer (1975)

Figura 64. Resistência ao cisalhamento na interface solo bulbo média de qs $=60 \mathrm{kPa}$ para as condições do caso em estudo pelo Método de Bustamante e Doix (1985)

Figura 65. Curva Carga contra Tempo dos Tirantes instrumentados da Seção 34.

Figura 66. Perdas e Ganhos de Carga dos Tirantes instrumentados da Seção 34.

Figura 67. Curva Carga contra Tempo dos Tirantes instrumentados da Seção 38.

Figura 68. Perdas e Ganhos de Carga dos Tirantes instrumentados da Seção 38. 
Figura 69. Curva Carga contra Tempo dos Tirantes instrumentados da Seção 45.

Figura 70. Perdas e Ganhos de Carga dos Tirantes instrumentados da Seção 45.

Figura 71. Curva Carga contra Tempo dos Tirantes instrumentados da Seção 48.

Figura 72. Perdas e Ganhos de Carga dos Tirantes instrumentados da Seção 48.

Figura 73. Curva Carga contra Tempo dos Tirantes instrumentados da Seção 51.

Figura 74. Perdas e Ganhos de Carga dos Tirantes instrumentados da Seção 51.

Figura 75. Curva Carga contra Tempo dos Tirantes instrumentados da Seção 54.

Figura 76. Perdas e Ganhos de Carga dos Tirantes instrumentados da Seção 54.

Figura 77. Curva Carga contra Tempo dos Tirantes instrumentados da Seção 57.

Figura 78. Perdas e Ganhos de Carga dos Tirantes instrumentados da Seção 57.

Figura 79. Curva Carga contra Tempo dos Tirantes instrumentados da Seção 60.

Figura 80. Perdas e Ganhos de Carga dos Tirantes instrumentados da Seção 60.

Figura 81. Curva Carga contra Tempo dos Tirantes instrumentados da Seção 66.

Figura 82. Perdas e Ganhos de Carga dos Tirantes instrumentados da Seção 66.

Figura 83. Curva Carga contra Tempo dos Tirantes instrumentados da Seção 69.

Figura 84. Perdas e Ganhos de Carga dos Tirantes instrumentados da Seção 69.

Figura 85. Diagramas de pressão de terras propostos para areias. 
Figura 86. Diagrama aparente para estruturas com múltiplos tirantes.

Figura 87. Envoltória de Forças medidas em campo e estimadas pelos Diagramas de empuxo propostos para a seção 57 pela FHWA e por Terzaghi e Peck (1967).

Figura 88. Envoltória de Forças medidas em campo e estimadas pelos Diagramas de empuxo propostos para a seção 45 pela FHWA e por Terzaghi e Peck (1967).

Figura 89. Valores retro analisados do coeficiente de empuxo lateral.

Figura 90. Valores retro analisados do ângulo de atrito mobilizado. 


\section{Lista de Tabelas}

Tabela 1. Tipos de solo contido (Gaba et al., 2003). 51

Tabela 2. Coeficientes de ancoragem kf (NBR 5629, 2006). 58

Tabela 3. Coeficiente de majoração do diâmetro do bulbo devido à injeção (BUSTAMANTE e DOIX, 1985, apud MORE, 2003). 61

Tabela 4. Fatores de calibração dos eletroníveis A01 a A16 91

Tabela 5. Sequência de ensaio de recebimento para os tirantes tipo $8 ø 8 \mathrm{~mm}$. 103

Tabela 6. Sequência de ensaio de recebimento para os tirantes tipo $10 ø 8 \mathrm{~mm}$. 103

Tabela 7. Tirantes que ficaram abaixo da "Linha C" da NBR 5629 no gráfico de carga contra deformação.

Tabela 8. Tirantes que ficaram acima da "Linha C" da NBR 5629 no gráfico de carga contra deformação.

Tabela 9. Tirantes que ficaram pertos da "Linha B" da NBR 5629 no gráfico de carga contra deformação.

Tabela 10. Avaliação dos Parâmetros de Resistência e de deformabilidade em Função do SPT (correlações empíricas).

Tabela 11. Capacidade de cargas dos tirantes analisados para cada nível da cortina segundo o Método da NBR 5629 (2006)

Tabela 12. Forças finais nos tirantes e somatório em toneladas.

Tabela 13. Valores de carga nos tirantes utilizando os diagramas de empuxo propostos pelo FHWA. 


\section{Lista de Símbolos}

\section{Romanos}

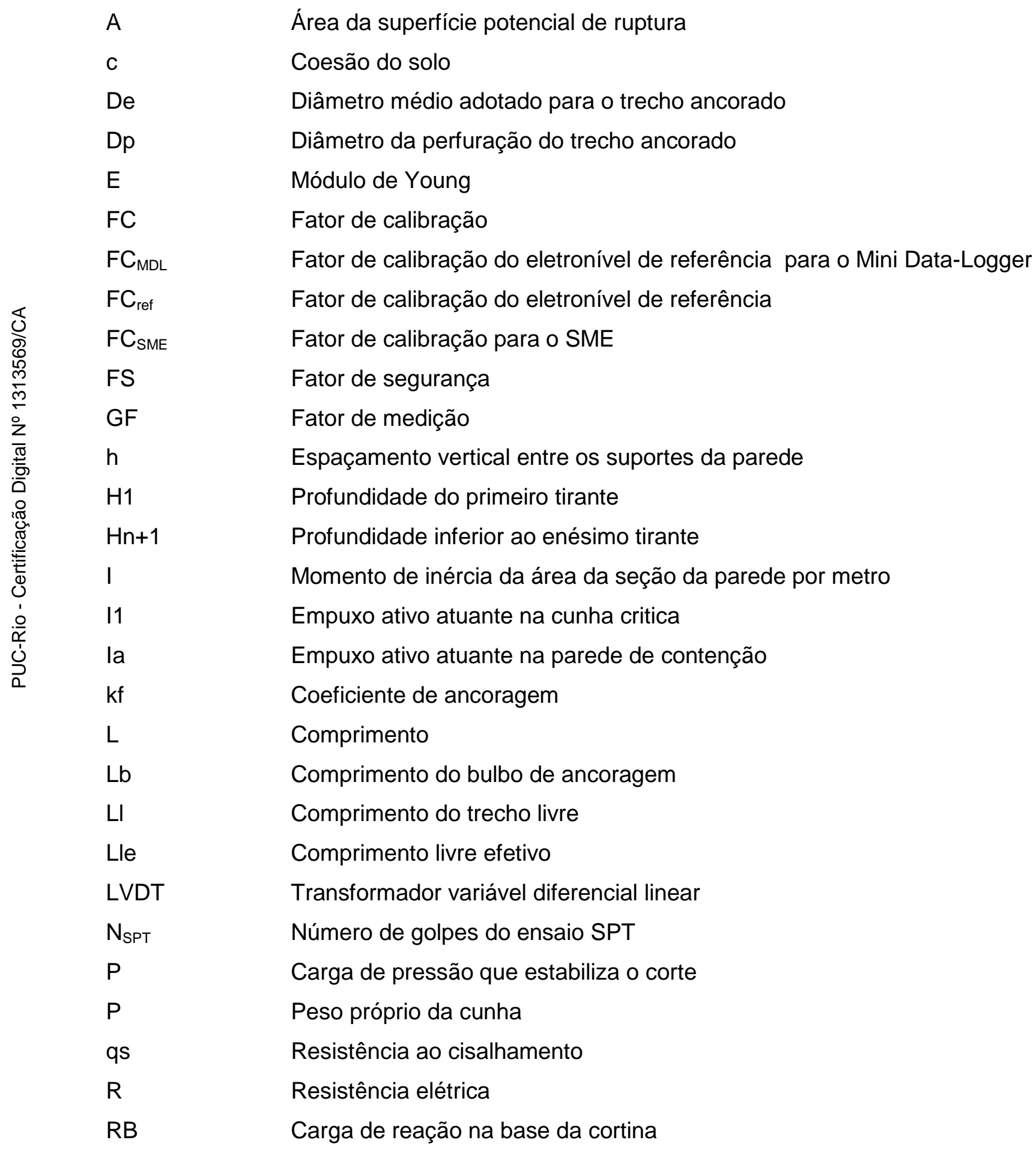


SME

$\mathrm{Su}$

T

$\mathrm{T}_{\mathrm{H}}$

TL

U

W

y
Sistema de Monitoramento de Eletroníveis

Resistência ao cisalhamento não drenada do solo

Capacidade de carga do bulbo

Componente horizontal da força do tirante

Carga total de pressão de terra

Perímetro médio da seção transversal da ancoragem

Peso da cunha critica

Deflexão 


\section{Gregos}

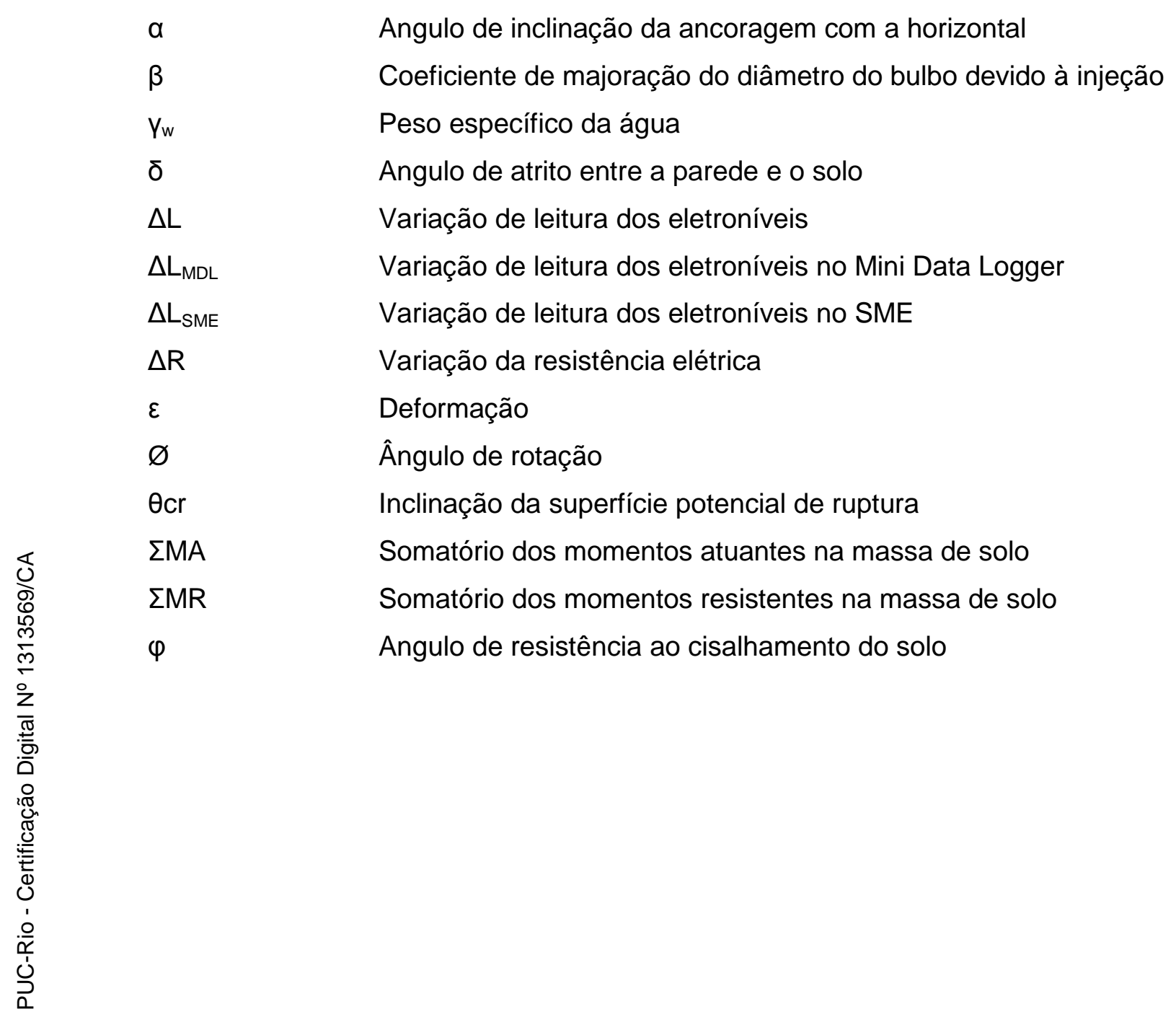

